\title{
Chromophobe Renal Cell Carcinoma
}

National Cancer Institute

\section{Source}

National Cancer Institute. Chromophobe Renal Cell Carcinoma. NCI Thesaurus. Code C4146.

A type of carcinoma that comprises a minority of renal cell carcinomas. It is characterized by loss of chromosomes 1 and Y. Based on the cytoplasmic characteristics of the neoplastic cells, this type of carcinoma is classified as classic (typical) or eosinophilic. It has a much better prognosis than other renal cell carcinomas. 